\title{
Генерализованное тревожное расстройство: о чем молчит пациент?
}

\section{Клинический случай № 1}

Пациентка К., 28 лет. Менеджер. Жалобы на плохой сон, повышенную утомляемость, постоянную «фоновую» головную боль, нарушение концентрации внимания, в последнее время - тахикардию. Отмечает нарастающий характер болезненных симптомов в течение нескольких месяцев. Начало их связывает с проблемами в семье (болезнь близкого родственника). В неврологическом статусе: напряжена, плечи приподняты, не может расслабиться при осмотре. Отмечается эмоциональное беспокойство, сбивчивый подробный рассказ о болезненных симптомах и переживаниях. Помимо легкого, еле заметного тремора кончиков пальцев вытянутых рук и оживленных сухожильных и периостальных рефлексов, другой симптоматики нет. Артериальное давление 130/90 мм рт. ст. Частота сердечных сокращений - 90 уд./мин.

Возможные диагнозы: «заболевание щитовидной железы», «вегетативно-сосудистая дистония», «синдром хронической усталости», «астеноневротический синдром» или что-то другое.

В ходе беседы выяснилось, что, помимо указанных жалоб, отмечает раздражительность, как будто «на взводе», испытывает постоянное внутреннее напряжение и волнение, не имеющее отношения к конкретным обстоятельствам, но практически ко всем аспектам жизни. Постоянное беспокойство испытывает всегда (сколько себя помнит). В анамнезе - приступы паники с ощущением потери равновесия, тахикардией, повышением артериального давления. Мать пациентки - беспокойная тревожная личность.

\section{Клинический случай № 2}

Пациентка В., 56 лет. Жалобы на головокружение, периодическое повышение артериального давления до 160/90 мм рт. ст. Подобные состояния продолжаются на протяжении минимум 10 лет, получает стационарное лечение с курсами сосудистой и метаболической терапии. Ухудшения связывает с периодами повышения напряженности на работе (главный бухгалтер). В неврологическом статусе - оживление сухожильныхи периостальных рефлексов, положительные аксиальные патологические рефлексы, напряжение мышц шейно-воротниковой зоны при пальпации.

Наиболее популярный диагноз при подобной симптоматике: «дисциркуляторная энцефалопатия в вертебробазилярном бассейне».

В ходе беседы выяснилось, что пациентку беспокоят также плохой сон, тахикардия, снижение памяти. На вопрос, считает ли себя тревожным человеком, отвечает утвердительно. Боится замкнутых пространств.

\section{Клинический случай № 3}

Пациентка С., 34 года. Не работает. Лечилась по поводу тревожно-депрессивного расстройства селективными ингибиторами обратного захвата серотонина. Жалобы на боль в поясничной области, которая беспокоит в течениепоследних 4 мес. Применение различных нестероидных противовоспалительных препаратов не приносило облегчения. Направлена на консультацию к нейрохирургу. Прооперированапо поводупротрузии диска $L_{v}-S_{\text {. }}$ После операции выраженность боли не уменьшилась, существенно нарушен сон, усилилась раздражительность. При неврологическом осмотре: ограничение движений в поясничном отделе позвоночника, напряжение мышц поясничного отдела с двух сторон, выпрямлен поясничный лордоз.

Присутствуют постоянная нервозность, невозможность расслабиться, дрожь, мышечное напряжение, потливость, периодически головокружение, постоянное волнение и тревожное предчувствие, повышенная утомляемость, нарушение сна.
Основываясь на нижеприведенных критериях, можно заключить, что у всех трех пациенток присутствуют признаки генерализованного тревожного расстройства (ГТР).

\section{Диагностические критерии ГТР}

Согласно Международной классификации болезней 10-го пересмотра, для установления диагноза «генерализованное тревожное расстройство» должны присутствовать:

- период с выраженной напряженностью, беспокойством и ощущением предстоящих неприятностей в повседневных событиях и проблемах;

- симптомы тревоги большинство дней за период по меньшей мере несколько недель подряд, обычно несколько месяцев.

Эти симптомы обычно включают: опасения (беспокойство о будущих неудачах, ощущение волнения, трудности в сосредоточении и др.), моторное напряжение (суетливость, головная боль напряжения, дрожь, невозможность расслабиться и др.).

Согласно DSM-5, диагностические критерии ГТР следующие:

А. Избыточная тревога и беспокойство (плохие предчувствия), появляющиеся на протяжении как минимум 6 мес при разных событиях или видах деятельности (на работе, в школе).

В. Беспокойство трудно контролировать.

С. Тревога и беспокойство связаны с $\geqslant 3$ из следующих шести симптомов (при условии, что часть симптомов представлена как минимум на протяжении 6 мес):

- возбужденность или нервозность, «состояние на пределе»;

- быстрая утомляемость;

- трудно сконцентрироваться («мозги отключаются»);

- раздражительность;

- мышечное напряжение;

- проблемы со сном (трудности в засыпании или нарушение продолжительности сна, или беспокойный, не приносящий удовольствия сон).

D. Тревога, беспокойство или физические симптомы, приводящие к клинически значимым расстройствам или нарушениям в социальной, трудовой или другой сфере жизнедеятельности.

Е. Перечисленные изменения не вызваны другими заболеваниями (например гипертиреоидизм), злоупотреблением наркотическими веществами или медикаментами.

F. Перечисленные изменения не могут быть объяснены наличием других психических расстройств (например тревога или беспокойство о наличии панических атак, отрицательная оценка при социальном тревожном расстройстве (социофобия), навязчивые состояния при обсессивно-компульсивном расстройстве, сепарационное тревожное расстройство, воспоминания о травмирующем событии при посттравматическом стрессовом расстройстве, увеличение массы тела при нервно-психической анорексии, жалобы на здоровье при соматических расстройствах).

В таблице представлен опросник, позволяющий выявить у пациента ГТР.

\section{Что стоит за "железной маской» вегетативных кризов и болевых синдромов?}

ГТР может быть коморбидно с другими заболеваниями, причем в основе его развития лежат личностные особенности.

Пациент с тревожным расстройством может прийти на прием к врачу практически любой специальности с соматическими и вегетативными симптомами:

- головокружение, тремор, внутренняя дрожь, снижение памяти, мышечные подергивания, судороги мышц (невролог); 
Таблица. Опросник для выявления ГТР

\begin{tabular}{|c|c|c|c|c|}
\hline $\begin{array}{c}\text { Как часто Вы отмечали } \\
\text { за собой в течение последних } \\
2 \text { нед следующее }\end{array}$ & $\begin{array}{l}\text { Не бес- } \\
\text { покои- } \\
\text { ли }\end{array}$ & $\begin{array}{l}\text { Не- } \\
\text { сколько } \\
\text { дней }\end{array}$ & $\begin{array}{l}\text { Более } \\
\text { полови- } \\
\text { ны дней }\end{array}$ & $\begin{array}{l}\text { Практиче- } \\
\text { ски каждый } \\
\text { день }\end{array}$ \\
\hline $\begin{array}{l}\text { Нервозность или тревожность, } \\
\text { ощущение, что Вы «на пределе» }\end{array}$ & 0 & 1 & 2 & 3 \\
\hline $\begin{array}{l}\text { Неспособность остановить } \\
\text { или контролировать беспокойство }\end{array}$ & 0 & 1 & 2 & 3 \\
\hline $\begin{array}{l}\text { Слишком сильное беспокойство } \\
\text { о разных вещах }\end{array}$ & 0 & 1 & 2 & 3 \\
\hline Невозможность расслабиться & 0 & 1 & 2 & 3 \\
\hline $\begin{array}{l}\text { Суетливость, Вам трудно } \\
\text { оставаться на месте }\end{array}$ & 0 & 1 & 2 & 3 \\
\hline Вы легко раздражаетесь & 0 & 1 & 2 & 3 \\
\hline $\begin{array}{l}\text { Опасение того, что может } \\
\text { случиться что-то ужасное }\end{array}$ & 0 & 1 & 2 & 3 \\
\hline Общее количество баллов & - & + & & + \\
\hline
\end{tabular}

- тахикардия, экстрасистолия, кардиалгия, лабильность артериального давления, акроцианоз, ощущение жара или холода (кардиолог);

- одышка, нехватка воздуха, удушье, ком в горле, зевота (терапевт, пульмонолог);

- тошнота, рвота, сухость во рту, боль в животе, запор (гастроэнтеролог);

- полиурия, цисталгия (уролог, нефролог) и др.

В то же время о таких симптомах, как ожидание предстоящих неблагоприятных событий, проблем и неудач практически во всех сферахжизни, постоянное ощущение волнения итревоги, невозможность расслабиться, пациенты, как правило, предпочитают молчать.

Отметим, что ГТ может возникать вне зависимости от конкретного жизненного события (боязнь несчастного случая или болезней, которые, по мнению больного, ожидаютего или его родственников).

Доминирующие симптомы изменчивы, но включают жалобы на устойчивую нервозность, невозможность расслабиться, нарушение концентрации внимания, утомляемость, мышечное напряжение, потливость, дрожь, головокружение и ощущение дискомфорта в эпигастральной области. Чаще это хроническое состояние с периодами обострений.

\section{Опасно ли постоянное ощущение тревоги?}

Постоянное ощущение тревоги опасно, поскольку чревато развитием серьезных осложнений - инфаркта миокарда, инсульта идр. Связь между тревогой и сердечно-сосудистыми заболеваниями впервые отмечена еще в XVI ст. Уильямом Гарвеем (William Harvey). У пациентов с кардиоваскулярными заболеваниями чаще развиваются расстройства тревожного характера, при этом у лиц с тревожностью отмечается более высокий риск возникновения сердечнососудистой патологии (Barger S.D., Sydeman S.J., 2005). Наличие в анамнезе ГТР или панического расстройства повышает вероятность развития артериальной гипертензии в 1,7 , ишемической болезни сердца - в 5,9 раза (Старостина Е.Г., 2006). Установлено, что наличие сопутствующего различным кардиоваскулярным заболеваниям тревожного расстройства повышает риск госпитализации больных на 28\%, тревожно-депрессивного расстройства - на $35 \%$ (Chamberlain A.M. et al., 2011). Тревожное расстройство, развившееся в течение 3 мес после инфаркта миокарда, повышает риск возникновения неблагоприятных сердечно-сосудистых событий на более чем $1 \frac{1}{3}$ (RoestA.M. etal., 2010). Тревога влияет на вариабельность сердечного ритма, что повышает риск возникновения жизнеопасных желудочковых аритмий и внезапной сердечной смерти (Lo Turco G., Grimaldi L., 2012). Отмечена связь между тревожными расстройствами и факторами риска сердечно-сосудистых заболеваний - чрезмерным употреблением алкоголя и курением.

Также представляет интерес связь между ГРТ и риском развития деменции (Gulpers B. et al., 2016).

\section{Нейробиологические основы соматических проявлений при тревожных расстройствах}

Воспаление при тревожных расстройствах является ключевым фактором активации микроглии (Michopoulos V. et al., 2017). Вслед за этим начинается весь каскад аккумуляции патологических белков в мозге.

За эмоциональную окраску поступающей в мозг информации ответственно миндалевидное тело, расположенное на внутренней поверхности височной доли головного мозга. Кроме этого, миндалина участвует в модуляции всех болевых импульсов, поступающих в мозг, будучи потенциальной «горячей точкой» В супраспинальном нисходящем пути, контролирующем боль. Когда миндалина активна - и при хронической боли, и при тревожном расстройстве снижается плотность серого вещества мозгав префронтальной коре и таламусе. Таким образом, хроническую боль и тревожно-депрессивное расстройство объединяют общие патогенетические звенья.

\section{Дифференциальная диагностика ГТР}

Следует проводить дифференциальную диагностику ГТР с:

- депрессией;

- другими тревожными расстройствами;

- общемедицинскими состояниями (гипертиреоидизм, гипопаратиреоидизм, феохромоцитома, гипогликемия, синдром Кушинга)

- парциальной эпилепсией;

- опухолью мозга, инсультом;

- применением медицинских препаратов (адренергические препараты, бронходилататоры, кортикостероиды, антигипертензивные препараты, препараты дигиталиса, психотропные препараты и их отмена).

\section{Лечение при ГТР}

Лечение пациентов с ГТР включает:

1. Психотерапию.

2. Применение антидепрессантов.

3. Применение прегабалина.

Прегабалин применяют для лечения в случае тревоги, ассоциированной с нарушениями сна, болевым синдромом (Baldwin D.S. et al., 2013). Показания к его применению: нейропатическая боль, ГТР, фибромиалгия, эпилепсия. Среди побочных эффектов, отмечаемых при применении прегабалина, - сонливость, неустойчивость (шаткость, атаксия), увеличение массы тела, отеки (в ряде случаев выраженные) (KanbayashiY. etal., 2014). Так, продолжительность терапии ассоциирована с сонливостью, возраст пациента и доза препарата - с неустойчивостью, уровень креатинина в плазме крови, сочетанное применение с другими препаратами, например антагонистами кальция, - с увеличением массы тела. Доза прегабалина имеет значение для контроля побочных эффектов и должна быть минимальной и при этом эффективной.

Важны также здоровый образ жизни, рациональное питание, полноценный сон, достаточная физическая активность, медитативные техники и контроль эмоциональных реакций.

\section{Список использованной литературы}

Старостина Е.Г. (2006) Тревога и тревожные расстройства в практике кардиолога. Кардиоваск. тер. проф., 5(3): 111-120.

Baldwin D.S., Ajel K., Masdrakis V.G. et al. (2013) Pregabalin for the treatment of generalized anxiety disorder: an update. Neuropsychiatr. Dis. Treat., 9: 883-892, doi: 10.2147/NDT.S36453.

Barger S.D., Sydeman S.J. (2005) Does generalized anxiety disorder predict coronary heart disease risk factors independently of major depressive disorder? J. Affect. Disord., 88(1): 87-91, doi: 10.1016/j.jad.2005.05.012.

Chamberlain A.M., Vickers K.S., Colligan R.C. et al. (2011) Associations of preexisting depression and anxiety with hospitalization in patients with cardiovascular disease. Mayo Clin. Proc., 86(11): 1056-1062. doi: 10.4065/ mcp.2011.0148.

Gulpers B., Ramakers I., Hamel R. et al. (2016) Anxiety as a Predictor for Cognitive Decline and Dementia: A Systematic Review and Meta-Analysis. Am. J. Geriatr. Psychiatry, 24(10): 823-842, doi: 10.1016/j.jagp.2016.05.015.

Kanbayashi Y., Onishi K., Hosokawa T. (2014) Factors predicting adverse events associated with pregabalin administered for neuropathic pain relief. Pain Res. Manag., 19(6): e164-e167. doi: 10.1155/2014/280549.

Lo Turco G., Grimaldi L. (2012) Spectral analysis of Heart Rate Variability in psychiatric patients: Autonomic nervous system evaluation in psychotic, anxiety and depressive disorders. Riv. Psichiatr., 47(2): 139-148. doi: 10.1708/1069.11718.

Michopoulos V., Powers A., Gillespie C.F. et al. (2017) Inflammation in Fear- and Anxiety-Based Disorders: PTSD, GAD, and Beyond. Neuropsychopharmacology, 42(1): 254-270, doi: 10.1038/npp.2016.146.

Roest A.M., Martens E.J., de Jonge P., Denollet J. (2010) Anxiety and risk of incident coronary heart disease: a meta-analysis. J. Am. Coll. Cardiol., 56(1): 38-46, doi: 10.1016/j.jacc.2010.03.034.

Информация для специалистов сферы здравоохранения 6-02-МЕД-РЕЦ-1219 


\section{1. Укажите диагностические критерии ГТР, согласно DSM-5:}

- избыточная тревога и беспокойство на протяжении как минимум 6 мес при разных событиях или видах деятельности

- избыточная тревога и беспокойство на протяжении как минимум 1 мес при разных событиях или видах деятельности

- беспокойство трудно контролировать

- беспокойство достаточно легко поддается контролю

- тревога и беспокойство связаны с $\geqslant 3$ из следующих симптомов (часть из них присутствует как минимум на протяжении 6 мес): возбужденность или нервозность, быстрая утомляемость, трудности с концентрацией внимания, раздражительность, мышечное напряжение, проблемы со сном

- тревога, беспокойство или физические симптомы, приводящие к клинически значимым расстройствам или нарушениям в разных сферах жизнедеятельности

- изменения не вызваны другими заболеваниями, в том числе психическими, злоупотреблением наркотическими веществами или медикаментами

\section{2. Симптомы тревоги обычно включают:}

- беспокойство о будущих неудачах, ощущение волнения

- трудности в сосредоточении

- моторное напряжение

- суетливость

- головную боль напряжения

- дрожь

- невозможность расслабиться

- все вышеперечисленное

\section{3. В основе ПТР лежат:}

- пережитое негативное жизненное событие

- боязнь возможных негативных событий в будущем

- личностные особенности

\section{4. Опасно ли постоянное ощущение тревоги?}

- нет, тревога не отражается в значительной мере на профессиональной, социальной и личной жизни пациента
- да, тревожное расстройство ассоциировано с появлением и усугублением уже имеющихся коморбидных расстройств

\section{5. Есть ли связь между хронической болью и тревожно-депрессивным расстройством?}

- да, эти два состояния объединяют общие патогенетические звенья и они часто сопутствуют друг другу

- как правило, эти состояния не связаны друг с другом

\section{6. С какими заболеваниями проводят дифференциальную диагностику ГТР?}

- депрессия

- другие тревожные расстройства

- общемедицинские состояния (гипертиреоидизм, гипопаратиреоидизм, феохромоцитома, гипогликемия, синдром Кушинга)

- парциальная эпилепсия

- органические поражения мозга

- применение медицинских препаратов

- все вышеперечисленное

\section{7. Какие побочные эффекты возможны при применении прегабалина? \\ - сонливость \\ - неустойчивость (шаткость, атаксия) \\ - увеличение массы тела \\ - отеки \\ - нет правильного ответа}

\section{8. Лечение пациентов с ГТР включает:}

- психотерапию

- применение антидепрессантов

- применение прегабалина

- психотерапию, применение антидепрессантов, применение прегабалина, здоровый образ жизни, рациональное питание, полноценный сон, достаточную физическую активность, медитативные техники, контроль эмоциональных реакций

Для получения сертификата ответьте на тестовые вопросы в режиме on-line на сайте журнала www.umj.com.ua или отправьте ксерокопию страниц с ответами вместе с контактной информацией по адресу:

01001, Киев-1, а/я “В»-82, ООО «МОРИОН»

\section{КОНТАКТНЫЕ ДАННЫЕ:}

ФИО

Почтовый адрес: индекс

область

район

город

улица

дом

Телефон

квартира

E-mail 